\title{
Fabrication and Characterization of Tungsten Heavy Alloys Using Chemical Reduction and Mechanical Alloying Methods
}

\author{
Zeinab Abdel Hamid ${ }^{1 *}$, Sayed Farag Moustafa ${ }^{2}$, Walid Mohamed Daoush ${ }^{2,3}$, \\ Fatema Abdel Mouez ${ }^{1}$, Mona Hassan ${ }^{1}$ \\ ${ }^{1}$ Corrosion Control and Surface Protection Department, Central Metallurgical R\&D Institute, Helwan, Cairo, Egypt \\ ${ }^{2}$ Powder Technology Department, Central Metallurgical R\&D Institute, Helwan, Cairo, Egypt \\ ${ }^{3}$ Department of Production Technology, Faculty of Industrial Education, Helwan University, Cairo, Egypt \\ Email: *forzeinab@yahoo.com
}

Received September 27, 2012; revised November 5, 2012; accepted November 14, 2012

\begin{abstract}
A novel reduction technique has been developed to synthesize nano-sized tungsten heavy alloys powders and compared with the same powders processed by mechanical alloying technique. In the first method, nano-sized tungsten heavy alloys powders have been obtained by reduction of precursors obtained by spray drying of several appropriate aqueous solutions, which were made from salts containing tungsten, cobalt, and nickel. By adjusting the stoichiometry of the component of the solutions, it is possible to obtain the desired chemical composition of the tungsten heavy alloys powders. In the second method, highly pure elemental powders of tungsten heavy alloys have been mechanically alloyed in a tumbler ball mill for different milling time. The investigated tungsten heavy alloy powders with the composition $(95 \% \mathrm{~W}-3.5 \% \mathrm{Ni}-1.5 \% \mathrm{Fe}),(93 \% \mathrm{~W}-4.5 \% \mathrm{Ni}-1.0 \% \mathrm{Fe}-1.5 \% \mathrm{Co})$, and $(90 \% \mathrm{~W}-6 \% \mathrm{Ni}-4 \% \mathrm{Cu})$ have been prepared using both methods. The prepared powders have been compacted at $70 \mathrm{bar}(200 \mathrm{MPa})$ and sintered in vacuum furnace at $1400^{\circ} \mathrm{C}$. Vacuum sintering was carried out to achieve full densification of the produced tungsten heavy alloys. The investigated materials were going to be evaluated the physical and mechanical properties of the sintered parts such as density; electrical conductivity, hardness, and transverse rupture strength. The results reveal that, the grain size of alloys fabricated by chemical reduction technique $(53.1-63.8 \mathrm{~nm})$ is smaller than that fabricated by mechanical alloying technique $(56.4-71.4$ $\mathrm{nm})$.
\end{abstract}

Keywords: Tungsten Heavy Alloys; Mechanical Alloying; Chemical Reduction; Powder Metallurgy; Hardness; Transverse Rupture Strength; Conductivity

\section{Introduction}

Tungsten heavy alloys (WHA's) illustrate the advantages of microencapsulated powders. WHA's are a kind of composite materials, consisting of two-phase microstructure of spherical tungsten particles embedded uniformly in a metallic matrix, such as W-Ni-Fe or W-Ni$\mathrm{Cu}$ or even $\mathrm{W}-\mathrm{Ni}-\mathrm{Cu}-\mathrm{Fe}$ solid solution $[1,2]$. Some elements are added to WHA's such as $\mathrm{Co}, \mathrm{Mo}, \mathrm{Cr}$, etc. The addition of cobalt to a W-Ni-Fe alloy is a common approach for slight enhancement of both strength and ductility. The presence of cobalt within the alloy provides solid-solution strengthening of the binder and slightly enhanced tungsten-matrix interfacial strength. Nickel, iron and copper serve as a binder matrix, which holds the brittle tungsten grains together and makes the alloys ductile and easy to machine. These alloys provide a unique

${ }^{*}$ Corresponding author. combination of properties, such as high density, excellent mechanical properties and good corrosion resistance, making them increasingly attractive in many practical applications, such as radiation shielding, mass balance for aerospace, vibrating masses for cell phones and kinetic energy penetrators [3-8]. Tungsten content in conventional heavy alloys varies from 90 to 98 weight percent and is the reason for their high density (between 16.5 and $18.75 \mathrm{~g} / \mathrm{cc}$ ).

There are several conventional methods for fabrication of tungsten heavy alloys, including mechanical alloying [9-11], electro-deposition technique [12,13], metal injection molding [10] and spray drying [14-16]. L. DongWon et al. [16] studied a novel reduction method to fabricate ultrafine tungsten heavy alloy powders, using cost effective source materials. The advantages of mechanical alloying method have the simple equipment and process and easy operation that make it suitable for mass produc- 
tion.

Using fine powder raw materials and/or novel techniques to prepare fine-or ultrafine-grained WHA's are the current trends. Fine-or ultrafine grained WHA's are usually prepared via sintering ultrafine/nano tungsten composite powders and controlling the growth of the tungsten grains $[10,15-21]$. By refining the microstructure of the tungsten heavy alloys, the mechanical properties can be improved.

The conventional processing route includes mixing the desired amount of elemental powders, followed by cold pressing and sintering. There are two essential phases during the sintering process: solid state phase, and liquid state phase. At melting, the liquid phase of the matrix, wet and infiltrate the solid grain structure by a combination of reaction and capillary forces, followed by a dissolving and growth of the solid particles by coalescence and Ostwald-ripening. The driving force for liquid phase sintering is not only the reduction of surface energy by capillary forces but also the reduction of chemical potential by dissolving of original and growth of equilibrium solid phase [22].

Liquid phase sintering is generally easier and more cost-effective than solid state. However, a certain degradation of the raw material will occur that is not the case with the solid state process. The sintering process occurs by mass transport at high temperature and sometimes a high pressure is also required as a driving force. The driving force for solid-state sintering is the reduction of surface free energy of the particles, which is achieved either by atomic diffusion transporting matter from inside the grains to fill the pores (densification) or rearrangement of the matter between different parts of the pore surfaces (without reducing pore volume) coarsens the microstructure.

In this study, a novel process was developed to synthesize nano-sized tungsten heavy alloys (WHA's) composite powders by chemical reduction method. For comparison, the same compositions of the investigated powders were also processed by mechanical alloying method. The prepared powders from both methods were cold compacted and sintered under vacuum. The fabricated composites have been evaluated in terms of density, mi- crostructure, hardness, transverse rupture strength, thermal and electrical conductivities.

\section{Materials and Methods}

Heavy tungsten alloy powders with composition of $95 \mathrm{~W}-$ $3.5 \mathrm{Ni}-1.5 \mathrm{Fe}, 93 \mathrm{~W}-4.5 \mathrm{Ni}-1.0 \mathrm{Fe}-1.5 \mathrm{Co}$, and $90 \mathrm{~W}-6 \mathrm{Ni}-4 \mathrm{Cu}$ in $\mathrm{wt} \%$ were prepared by chemical reduction and mechanical alloying (MA) techniques. Tungsten, iron, cobalt and nickel have been characterized in terms of flow rate, average grain sizes and apparent density. Table 1 summarizes these characterizations. A scanning electron microscope (SEM) equipped model JEOL, JSM-5410 was used to study surface morphologies of the powders. A JEOL (JEM 2010) transmission electron microscope was used to analyze the powder size. The phase structure was analyzed by X-ray diffractometer (XRD) model PAN analytical X'pert PRO with $\mathrm{Cu} \mathrm{K} \alpha 1$ target with wavelength $1.5046 \mathrm{~A}$ and operated at $45 \mathrm{kV}$ and $40 \mathrm{~mA}$. The step size, rate and range were $0.02^{\circ}, 0.05^{\circ} \mathrm{s}^{-1}$ and $10^{\circ}$ $100^{\circ}$, respectively.

\subsection{Tungsten Heavy Alloys Fabrication}

\subsubsection{Chemical Reduction Method}

In the chemical reduction method, a novel process was developed to synthesize tungsten heavy alloys nanocomposite powders by controlled reduction of precursors obtained by spray drying of several appropriate aqueous solutions, which was made from salts containing tungsten, cobalt, nickel, and iron. Tungsten powder was obtained from solution of ammonium metatungstate $\left[\left(\mathrm{NH}_{4}\right)_{6} \cdot\left(\mathrm{H}_{2} \mathrm{~W}_{12} \mathrm{O}_{40}\right)\right]$, whereas Co-powders was made from cobalt nitrate $\left[\mathrm{Co}\left(\mathrm{NO}_{3}\right)_{2} \cdot 6 \mathrm{H}_{2} \mathrm{O}\right]$ solution, and the Ni powder was made from nickel acetate $\left[\mathrm{Ni}\left(\mathrm{CH}_{3} \mathrm{COO}\right)_{2} \cdot 4 \mathrm{H}_{2} \mathrm{O}\right]$ solution, $\mathrm{Fe}$ and $\mathrm{Cu}$ were formed from their oxides $\mathrm{Fe}_{2} \mathrm{O}_{3}$ and $\mathrm{CuO}$ respectively. Hydrogen gas was used as the reductant gas. By adjusting the stoichiometry of the component of the solutions and iron or copper oxide, it is possible to obtain the desired chemical composition of the tungsten heavy alloys powders.

Table 1. Characteristics of starting powders.

\begin{tabular}{cccc}
\hline Items & Tungsten powder & Nickel powder & Iron powder \\
\hline Vendor & H. C. Starck GmbH & INCO Europe Ltd. & New Metals \& Chemicals UK \\
Purity $\%$ & 99.85 & 99.7 & 99.7 \\
Theoretical density & 19.3 & 8.9 & 99.6 \\
Flow rate (s/50g) & $\infty$ & $\infty$ & $\infty$ \\
Average particle size, $\mu \mathrm{m}$ & $1-3$ & 2.5 & $0.3-0.5$ \\
\hline
\end{tabular}




\subsubsection{Mechanical Alloying Method}

In the mechanical alloying method, highly pure elemental powders of tungsten of $1-3 \mu \mathrm{m}$ particle sizes, nickel of $2.5 \mu \mathrm{m}$, cobalt of $2 \mu \mathrm{m}$, iron of $0.3-0.5 \mu \mathrm{m}$ and copper of $0.2-0.4 \mu \mathrm{m}$ in average diameter particles of the investigated chemical compositions of WHA's have been mechanically alloyed by rod milling for different milling time. The elemental powders of $\mathrm{W}, \mathrm{Ni}, \mathrm{Fe}$ and $\mathrm{Co}$ weighed to the target compositions and milled in a milling machine. The diameter of the mill was $255 \mathrm{~mm}$, and Cr-steel balls of $8 \mathrm{~mm}$ in diameter were used as the milling media. The milling speed was $120 \mathrm{rpm}$, milling time varied up to $72 \mathrm{~h}$, rod-to-powder ratio was $20: 1$ by weight, and the ball filling ratio was $15 \%$ by volume.

The prepared powders from both methods were blended with $0.5 \mathrm{wt} \%$ paraffin wax and cold compacted using Hydraulic press at compaction pressure of 70 bar. The green compacts were sintered using solid-state sintering at a temperature $1400^{\circ} \mathrm{C}$ for $1 \mathrm{~h}$ under vacuum as illustrates in the schematic diagram of the sintering cycle in Figure 1.

\subsection{Characterization of Alloys}

The evaluation testing of the powder and consolidated materials includes: density, hardness, transverse rupture strength as well as electrical and thermal conductivities. Moreover, extensive metallographic studies were performed using both optical and SEM microscopy for the sintered materials in order to measure the contiguity and structure homogeneity.

\subsubsection{Densities Measurements}

The densities of the sintered powders were measured according to MPIF Standards 42, 1998, using Archimedes rule. The density $(\delta)$ of the samples was calculated according to the following formula [22]:

$$
\delta=W_{a} /\left(W_{a}-W_{w}\right) \mathrm{gm} / \mathrm{cm}^{3}
$$

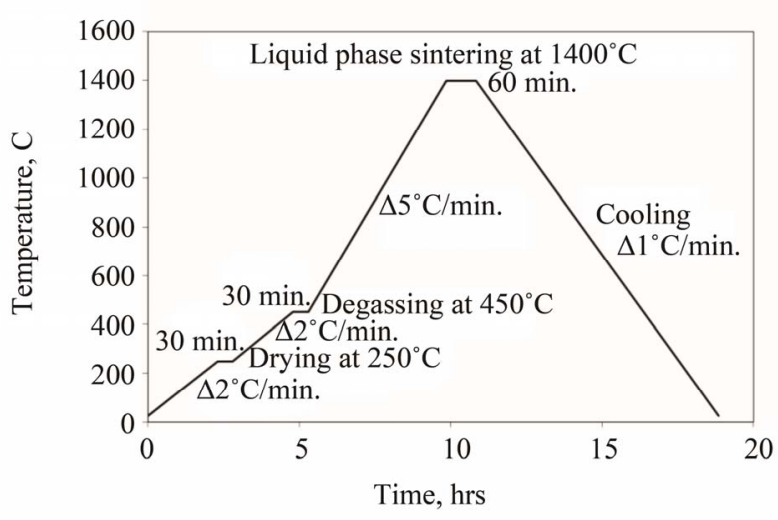

Figure 1. The heating cycle for the vacuum sintering process at $1400^{\circ} \mathrm{C}$ for the investigated tungsten heavy alloys. where $W_{a}$ and $W_{w}$ are the weights in air and water respectively.

The compact sinterability was also expressed in the terms of densification parameter which is calculated as follows:

$$
\text { Densification }=\delta_{s}-\delta_{g} / \delta_{t h}-\delta_{g}
$$

where $\delta_{s}$ is the sintered density, $\delta_{g}$ is the green density and $\delta_{t h}$ is the theoretical density.

\subsubsection{The Electrical Resistivity Measurements}

The electrical resistivity of the sintered materials was measured using the four-probe method by using Omega CL 8400 micrometer device. The resistivity $(\rho)$ was calculated according to the following equation by using High Precision Micro-ohmmeter.

$$
\rho=(R \cdot A) / L
$$

where, $R$ is the resistance in micro ohm, $L$ is the measured length in $\mathrm{cm}, A$ is the cross section area in $\mathrm{cm}^{2}$, and $\rho$ is the resistivity in $\mu \Omega \mathrm{cm}$.

\subsubsection{The Microhardness Measurements}

The Vickers microhardness of the alloys was determined by an indentation technique at $500 \mathrm{gf}$ load with a diamond pyramid indenter technique, Tukon Series B200 microhardness tester.

\subsubsection{Transverse Rupture Strength (TRS) Measurements}

The rupture test was performed using compression testing machine and a test fixture, according to MPIF Standard 41. All the samples of the powders were compacted into rectangular compacts of dimension of $(30 \times 10 \times 6)$ $\mathrm{mm}^{3}$. In the transverse rupture fixture, the test bar was placed centrally located and perpendicular to the supporting rods with the top up. The fixture with the test bar was placed between the plates of the compression testing machine and the load was applied at constant rate of 2.5 $\mathrm{mm} / \mathrm{min}$, until the test bar fractured. The transverse rupture strength for sintered samples was calculated according to the following expression [22]:

$$
T R S=\frac{3 P L}{2 t^{2} W}
$$

where: TRS is Transverse rupture strength in $\mathrm{N} / \mathrm{mm}^{2}$.

$P$ is the fracturing (rupture) load $(\mathrm{N})$.

$L$ is the distance between the supporting rods (25.4 $\mathrm{mm})$.

$t$ is the thickness of the sample in (mm).

$W$ is the width of the sample in (mm).

\subsubsection{Thermal Conductivity}

The thermal conductivity was calculated from electrical 
resistivity measurement using Wiedemann and Franz equation which derived a relation equation between the thermal and electrical conductivities [23]. The Wiedemann-Franz equation is as follows:

$$
\frac{\lambda}{\sigma T}=\frac{\pi^{2} k_{B}^{2}}{3 e^{2}}=L=2.443 \times 10^{-8} \mathrm{~J} \Omega / \mathrm{K}^{2} \mathrm{~s}
$$

where, $\lambda$ is thermal conductivity $(\mathrm{W} / \mathrm{mK}), \sigma$ is electrical conductivity $\left(\mu \Omega \cdot \mathrm{cm}^{-1}\right), T$ is absolute temperature in degree Kelvin, $\mathrm{KB}$ is Boltzmann constant, and $\mathrm{L}$ is Lorentz number.

\section{Results and Discussion}

\subsection{Fabrication of Tungsten Heavy Alloys Using Chemical Reduction Method}

Firstly, Salts of cobalt nitrate, ammonium metatungstate, and nickel acetate were used to prepare cobalt, tungsten and nickel powders by chemical method. The salt solution of each one was spray dries using the centrifugal atomization which was adjusted at rotating velocity of $11,000 \mathrm{rpm}$, and feeding rate of $30 \mathrm{CC} / \mathrm{min}$. The spray dried powder of each composition was collected and heated up in air at $800^{\circ} \mathrm{C}$ to form oxide powders. XRD spectra of each salt after heated are shown in Figure 2. XRD patterns illustrate the peaks of $\mathrm{W}$ oxide at different $2 \theta$ angles $24^{\circ}, 33^{\circ}, 42^{\circ}, 48^{\circ}, 55.5^{\circ}, 61^{\circ}$ (Figure 2(a)), cobalt oxide at $18.98^{\circ}, 31.28^{\circ}, 36.86^{\circ}, 38.54^{\circ}, 44.82^{\circ}$, $59.35^{\circ}$ and $65.25^{\circ}$ (Figure 2(b)) and nickel oxide at 26.6 $37.25^{\circ}$, and $43.29^{\circ}, 62.88^{\circ}$ and $75.40^{\circ}$ (Figure 2(c)). The oxide powders were reduced in hydrogen atmosphere for $30 \mathrm{~min}$ at $750^{\circ} \mathrm{C}$ to obtain pure metal powder.

Similarly, synthesis of tungsten-base nanocomposite alloy powders have been prepared by chemical reduction of precursors obtained by spray drying of several appropriate aqueous solutions, which were made from salts containing tungsten, cobalt and nickel, whereas iron and copper were added as oxides. Three tungsten-base alloy powders were obtained, namely, $(95 \% \mathrm{~W}-3.5 \% \mathrm{Ni}-$ $1.5 \% \mathrm{Fe}),(93 \% \mathrm{~W}-4.5 \% \mathrm{Ni}-1 \% \mathrm{Fe}-1.5 \% \mathrm{Co})$, and $(90 \% \mathrm{~W}-$ $6 \% \mathrm{Ni}-4 \% \mathrm{Cu}$ ) alloys. Dried solution salts were further heated up in open air at $800^{\circ} \mathrm{C}$ for $2 \mathrm{hrs}$ in order to obtain corresponding alloy oxides. Figure 3 illustrates the XRD of the three investigated oxide alloys. The apparent crystallite size of the oxides of WHA's prepared by chemical reduction technique reaches to the nanoscaled dimension as shown in TEM images (Figure 4).

The resulted oxide alloy powders were reduced in tube furnace using hydrogen gas as reductant. According to the analysis of the X-ray diffraction pattern (Figure 5) it can be concluded that the complete reduction was achieved at that condition. The apparent crystallite size of the WHA's powders prepared by chemical reduction technique after reduction using TEM is shown in Figure
6. The images reveal that the crystal size reaches to the nano-scaled dimension.

The reduction of $\mathrm{WO}_{3}$ by $\mathrm{H}_{2}$ gas is a complex process, while Lassner and Schubert proved that, the reduction of $\mathrm{WO}_{3}$ can be divided into two steps: firstly, oxygen transport by solid state diffusion $\left(\mathrm{WO}_{3} \rightarrow \mathrm{WO}_{3-x}\right)$, secondly, tungsten transport by chemical vapor transport $\left(\mathrm{WO}_{3-x} \rightarrow \mathrm{W}\right)$ as shown in the following chemical reactions [24]:

$$
\begin{gathered}
\mathrm{WO}_{3(s)}+\mathrm{H}_{2(g)} \rightarrow \mathrm{WO}_{3-x(s)}+x \mathrm{H}_{2} \mathrm{O}_{(g)} \\
\mathrm{WO}_{3-x(s)}+\mathrm{H}_{2(g)} \rightarrow \mathrm{W}_{(s)}+(3-x) \mathrm{H}_{2} \mathrm{O}_{(g)} \\
\mathrm{WO}_{3-x(s)}+(1-x) \mathrm{H}_{2} \mathrm{O}_{(g)} \rightarrow \mathrm{WO}_{2}(\mathrm{OH})_{2(g)}+x \mathrm{H}_{2} \mathrm{O}_{(g)} \\
\mathrm{WO}_{2}(\mathrm{OH})_{2(g)}+3 \mathrm{H}_{2} \mathrm{O}_{(g)} \rightarrow W_{(s)}+4 \mathrm{H}_{2} \mathrm{O}_{(g)}
\end{gathered}
$$
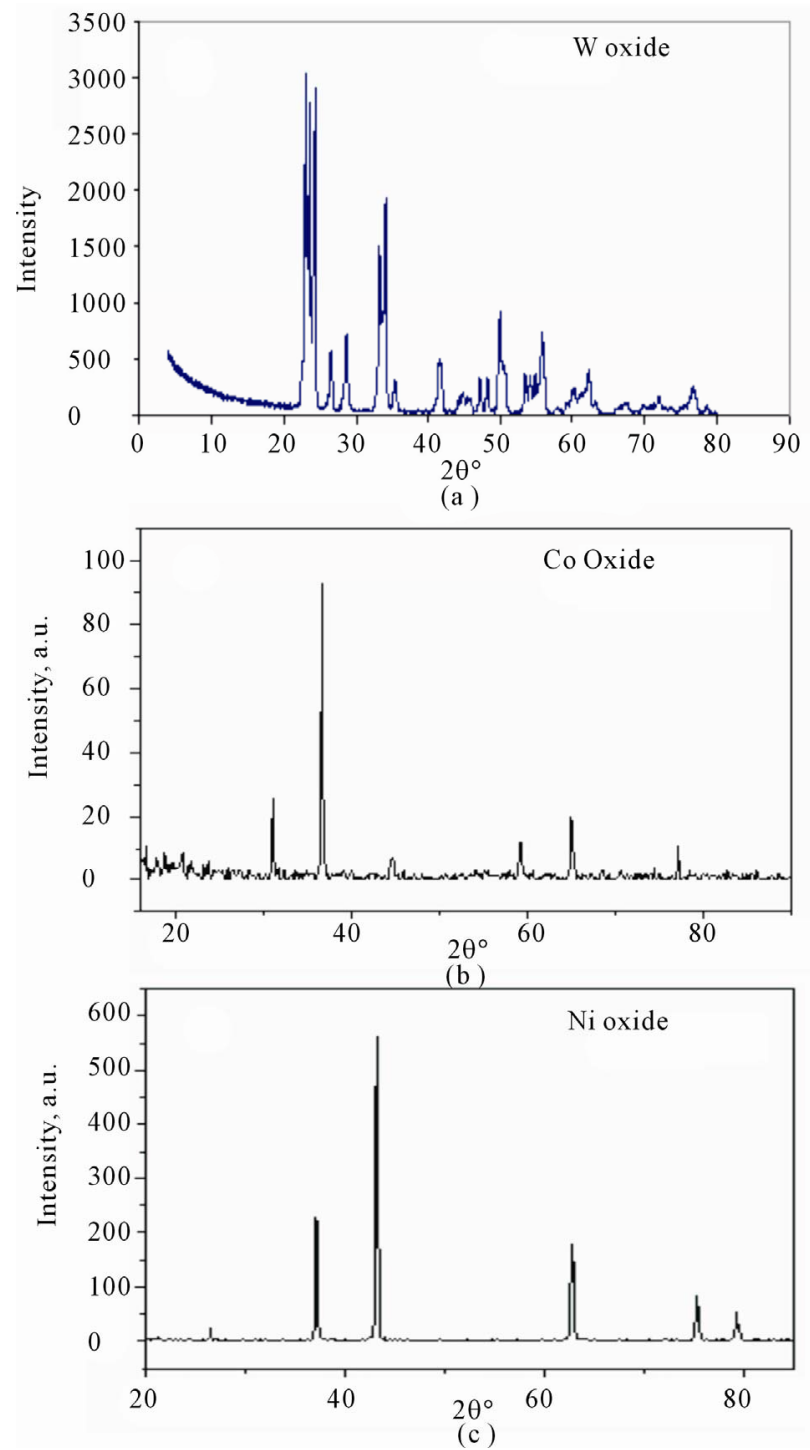

Figure 2. XRD of the oxide powders; where (a) tungsten oxide, (b) cobalt oxide, and (c) nickel oxide. 


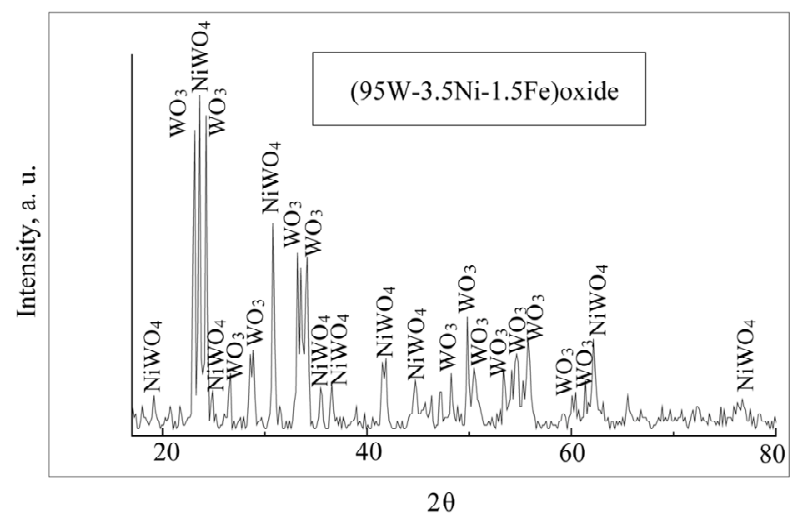

(a)

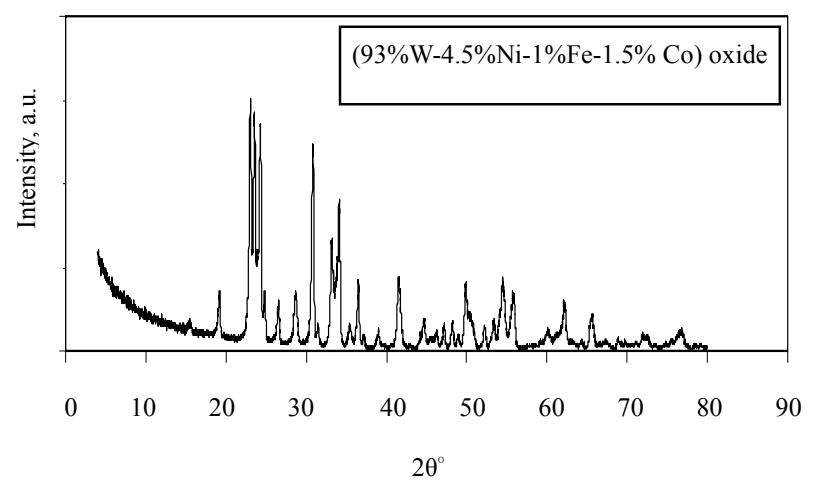

(b)

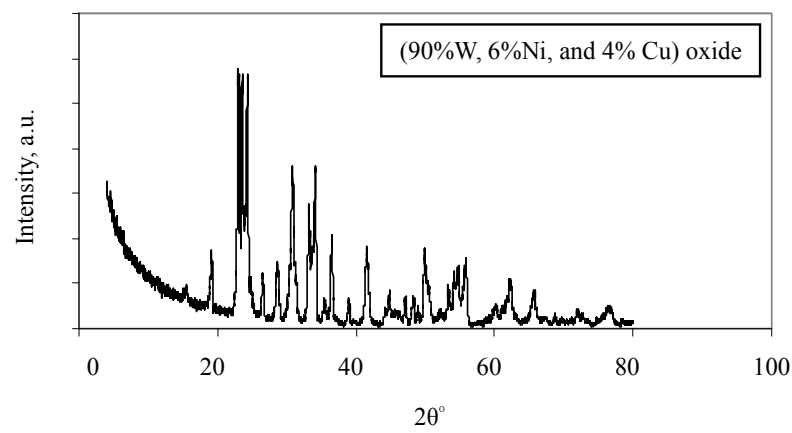

(c)

Figure 3. XRD of the three investigated oxide alloys.

Additionally, during the synthesis process, it can be assumed that nickel, cobalt and iron components are reduced before the tungsten due to the low reduction temperatures of their oxides.

\subsection{Fabrication of Tungsten Heavy Alloys Using Mechanical Alloying Method}

Figure 7 shows scanning electron microscopy images of the tungsten, nickel, iron and cobalt powder used in this study. The grain sizes of elemental powders were ranged from 2 up to $10 \mu \mathrm{m}$. In this investigation, three alloys composite powders were prepared from these highly pure elemental powders, namely; $(95 \% \mathrm{~W}-3.5 \% \mathrm{Ni}-1.5 \% \mathrm{Fe})$,

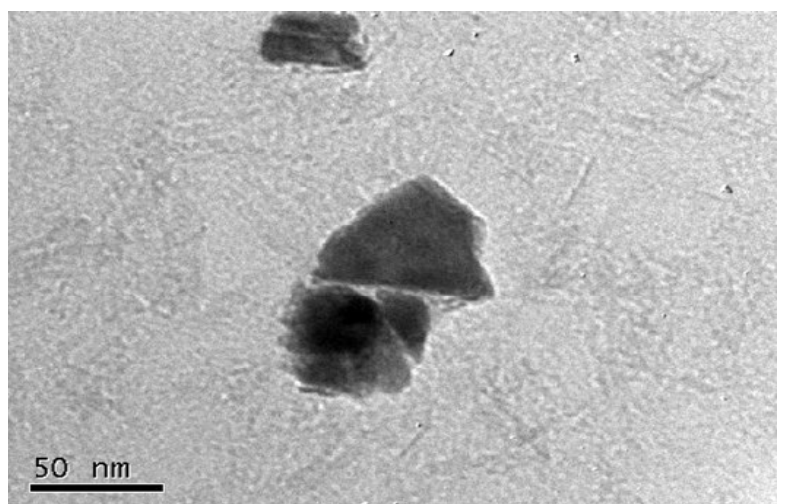

(a)

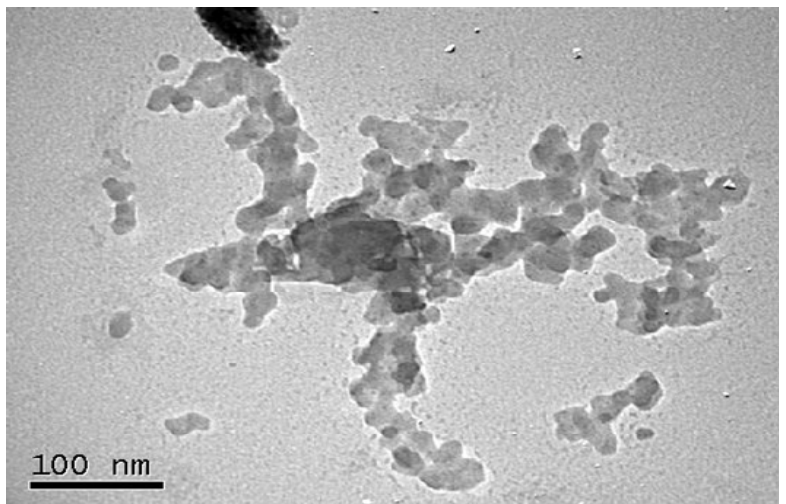

(b)

Figure 4. TEM images of different WHA's oxides compositions prepared by chemical reduction method, where: (a) (93\%W-4.5\% Ni-1\%Fe-1.5\%Co) oxide and (b) (90\%W, $6 \% \mathrm{Ni}$, and $4 \% \mathrm{Cu}$ ) oxide.

$(93 \% \mathrm{~W}-4.5 \% \mathrm{Ni}-1 \% \mathrm{Fe}-1.5 \% \mathrm{Co})$, and $(90 \% \mathrm{~W}, 6 \% \mathrm{Ni}$, and $4 \% \mathrm{Cu})$.

The sequences of structural sizes, phase transformation and the behavior of mechanically alloyed powders have been assessed using XRD and TEM microscopy. The XRD analysis of different MA's milled for $72 \mathrm{hrs}$ are shown in Figure 8. Due to the percents of other elements in the powders are too small to be detected; only diffraction peaks of $\mathrm{W}$ phase are observed in the XRD patterns. The intensity of diffraction peaks becomes gradually low with the increase of milling time, indicating a continuous decrease in the $\mathrm{W}$ grain size. After milling for about 72 hrs, the average particle size approaches the minimum, owing to the role of colliding and rolling of milling balls. The crystallite size of the three different MA's powder which calculated by the Scherer formula $(d=0.9 \lambda / \beta \cos \theta)$ as a function of milling time is shown as Table 2. The results reveal that the grain size decreases with increasing milling time in all three groups. The apparent crystallite size of these MA's reaches to the nano-scaled dimension. This agrees closely with measuring by TEM observation. It is clearly seen that morphology appears threadlike and flocculencelike. TEM morphologies show that 


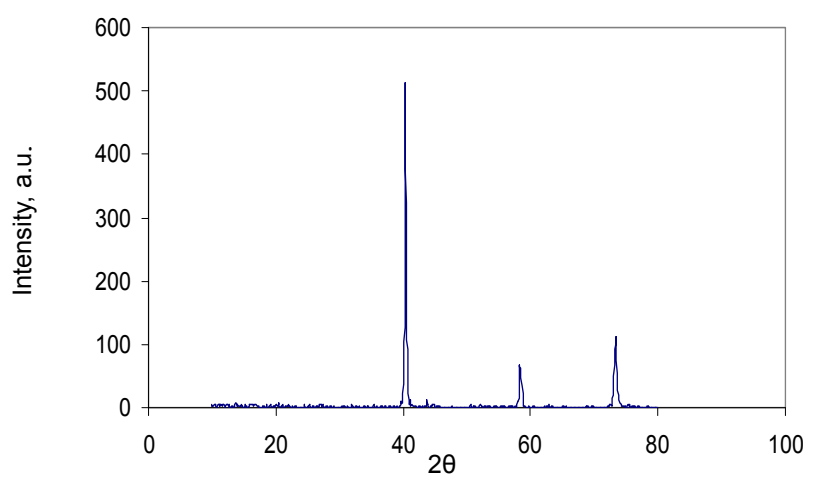

(a)

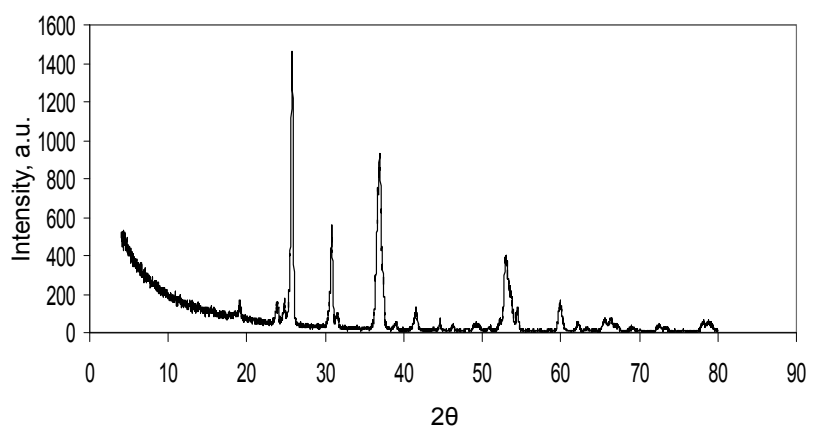

(b)

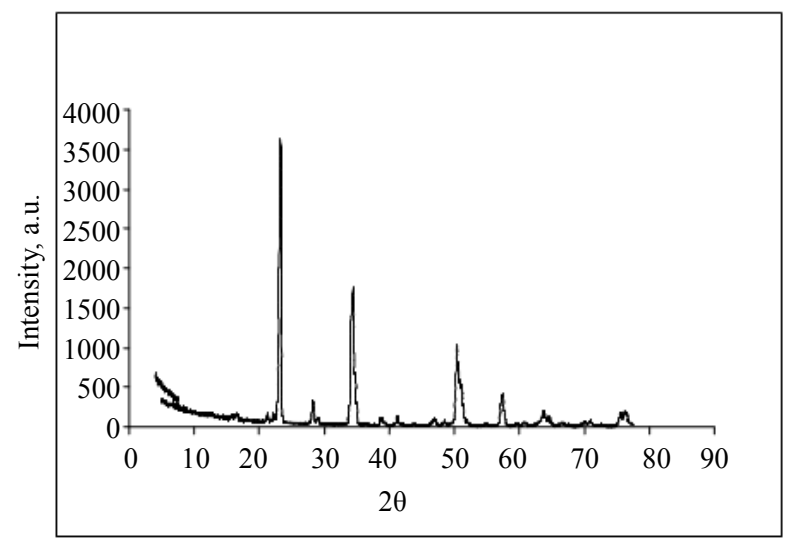

(c)

Figure 5. XRD of the three investigated WHA's powder after reduction where: (a) $(95 \mathrm{~W}-3.5 \mathrm{Ni}-1.5 \mathrm{Fe})$, (b) $(93 \% \mathrm{~W}$ $4.5 \% \mathrm{Ni}-1 \% \mathrm{Fe}-1.5 \% \mathrm{Co})$, and (c) $(90 \% \mathrm{~W}, 6 \% \mathrm{Ni}, 4 \% \mathrm{Cu})$.

there is a significant reduction in grain sizes elemental powders of each alloy, as can be seen in Figure 9. It can be noted that all ingredients are in the nanosize grains. The average grain size of the MA's after $72 \mathrm{hrs}$ milling is in the range of $63-72 \mathrm{~nm}$.

\subsection{Compaction and Solid-State Sintering}

The prepared powders made by either chemical reduction or mechanical methods were cold compacted at 70 $\mathrm{MPa}$ in cylindrical shape of $10 \mathrm{~mm}$ diameter and $10 \mathrm{~mm}$ length and rectangular of $30 \times 12 \times 6 \mathrm{~mm}$. The Cylin-
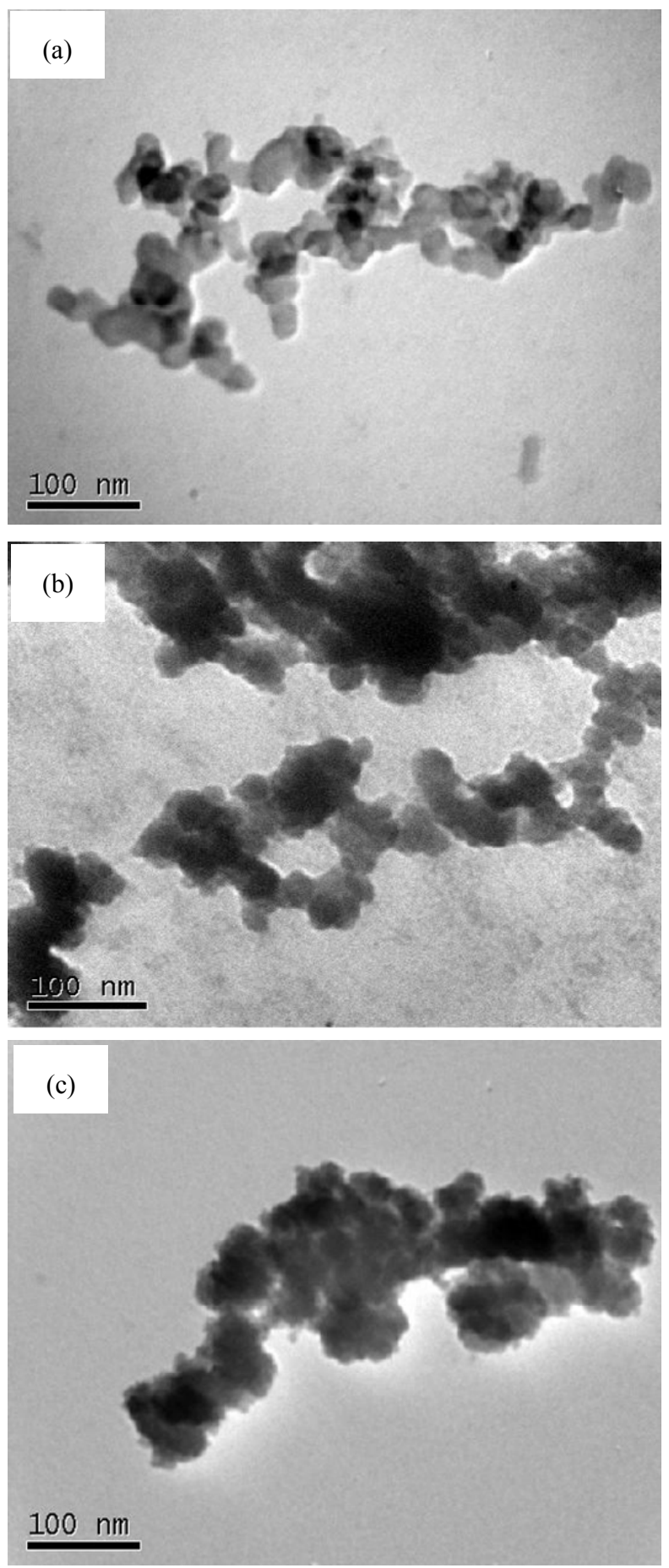

Figure 6. TEM image of the three investigated WHA's powder after reduction where: (a) (95W-3.5Ni-1.5Fe), (b) $(93 \% \mathrm{~W}-4.5 \% \mathrm{Ni}-1 \% \mathrm{Fe}-1.5 \% \mathrm{Co})$, and (c) $(90 \% \mathrm{~W}, 6 \% \mathrm{Ni}$, and $4 \% \mathrm{Cu})$.

drical shape samples were used for measuring density, hardness and microstructure investigation, whereas the rectangular ones were used for measuring transverse rupture strength, electrical resistivity, and thermal conductivity. 

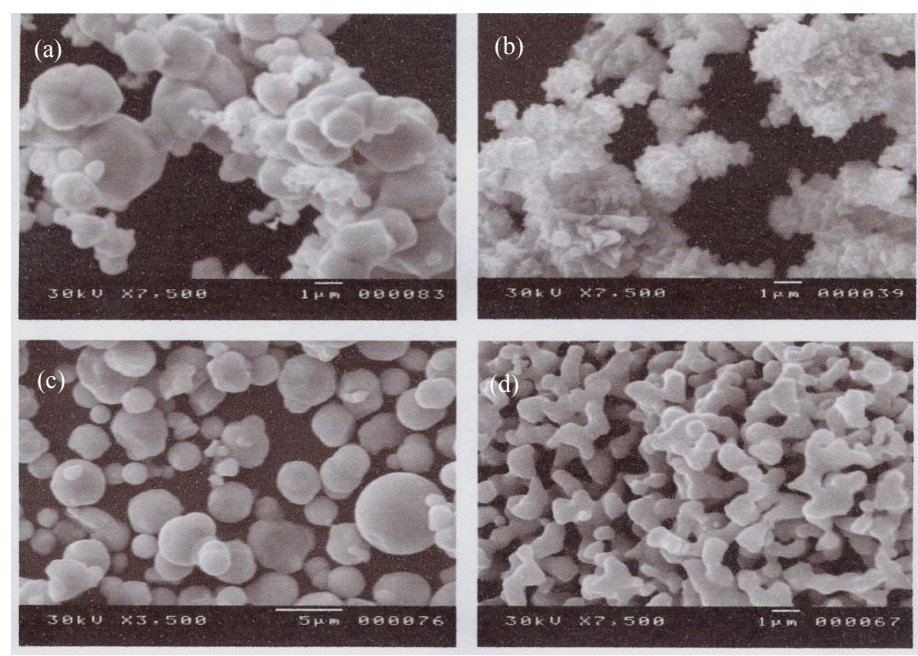

Figure 7. SEM micrographs of the as received powders: (a) tungsten, (b) nickel, (c) iron and (d) cobalt powders.
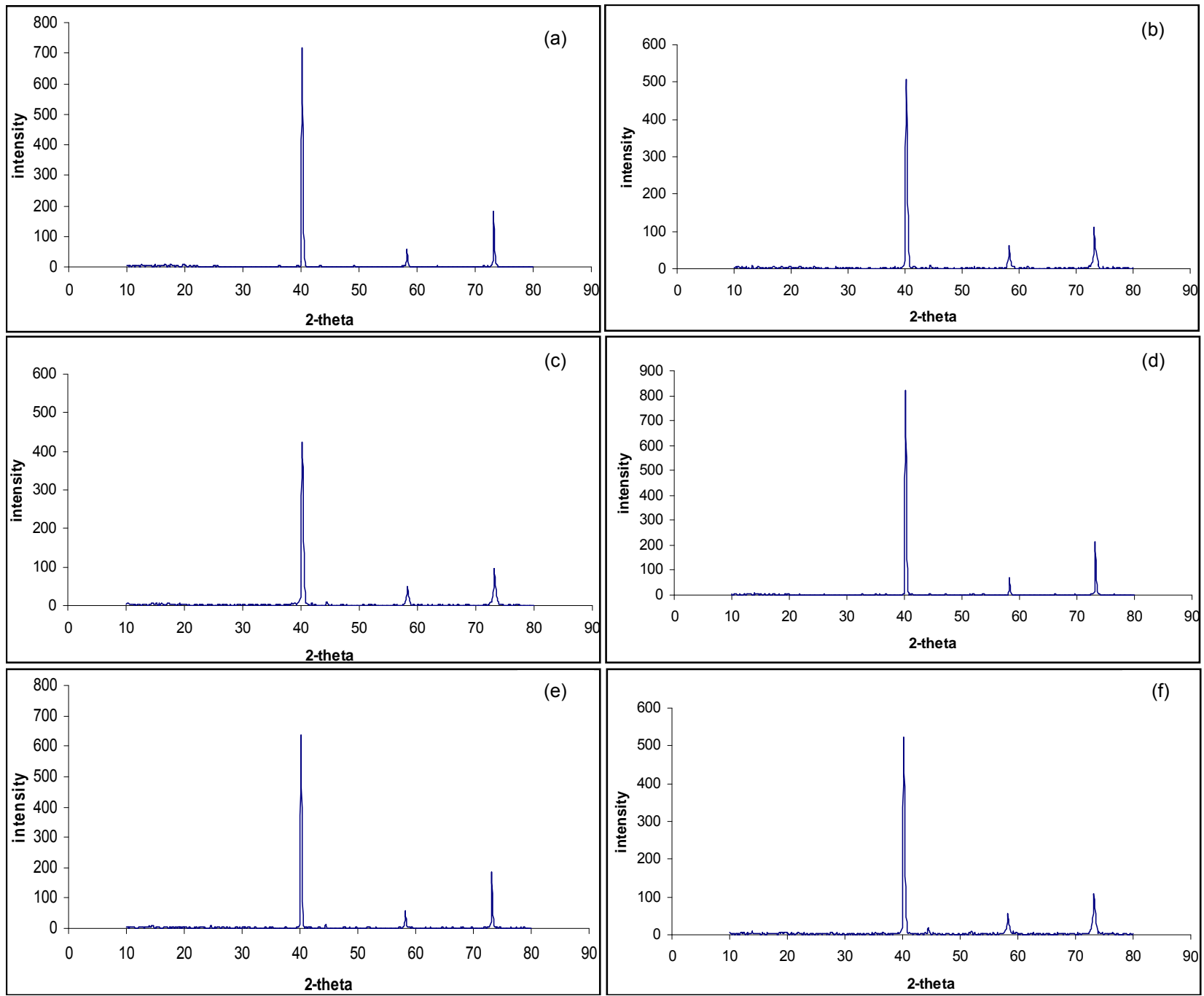

Figure 8. XRD of different MA's before and after milling for $72 \mathrm{~h}$, where: (a) MA (W-3.5Ni-1.5Fe) before milling, (b) MA (95W-3.5Ni-1.5Fe) after milling, (c) MA (93\%W-4.5\%Ni-1\%Fe-1.5\%Co) before milling, (d) MA (93\%W-4.5\% Ni-1\%Fe$1.5 \% \mathrm{Co})$ after milling, (e) MA $(90 \% \mathrm{~W}, 6 \% \mathrm{Ni}$, and $4 \% \mathrm{Cu})$ before milling, and f) MA $(90 \% \mathrm{~W}, 6 \% \mathrm{Ni}$, and $4 \% \mathrm{Cu})$ after milling. 

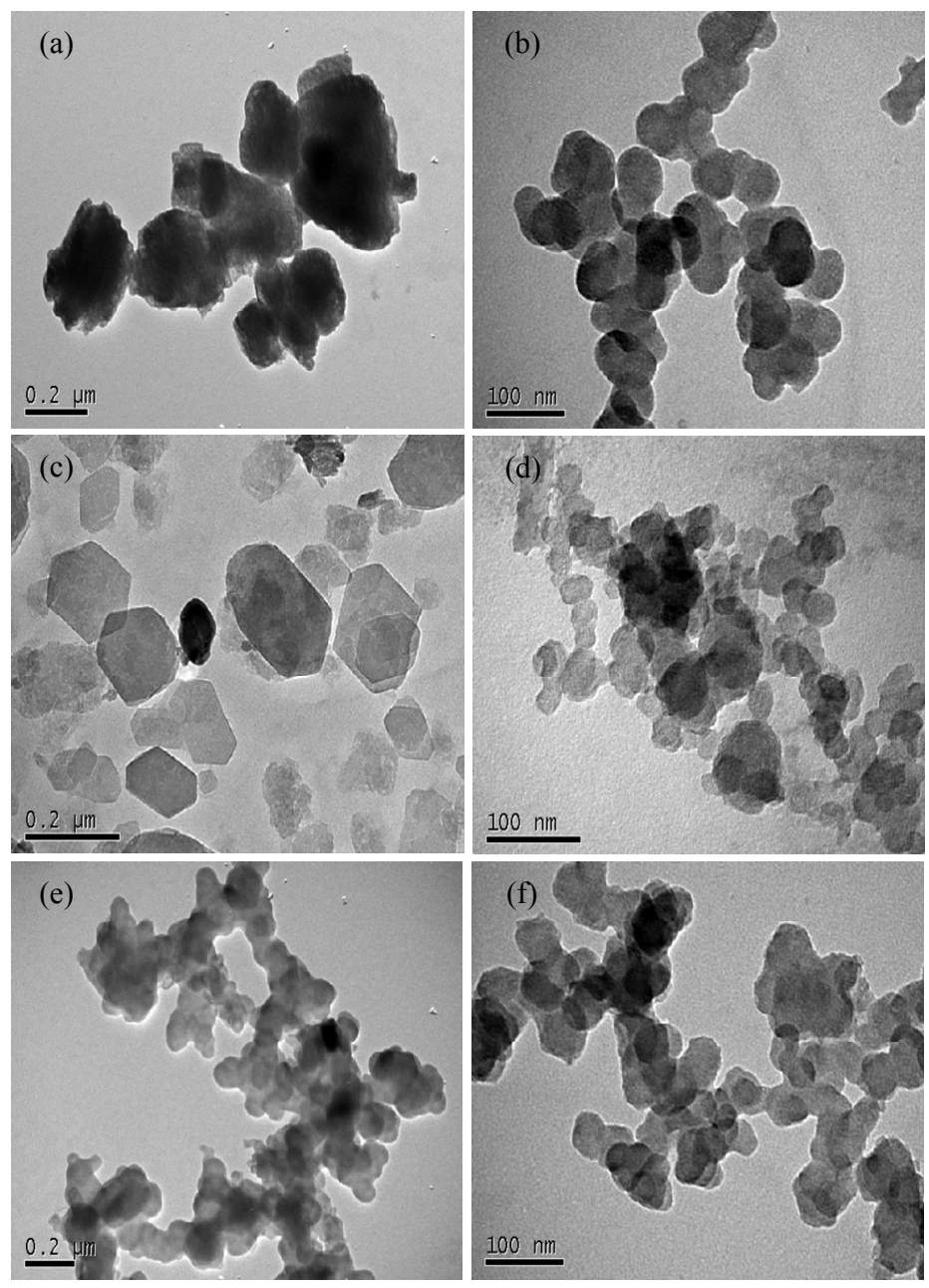

Figure 9. TEM images of different MA's before and after milling for $72 \mathrm{~h}$, where: (a) MA (95W-3.5Ni-1.5Fe) before milling, (b) MA (95W-3.5Ni-1.5Fe) after milling, (c) MA (93\%W-4.5\% Ni-1\%Fe-1.5\%Co) before milling, (d) MA (93\%W-4.5\%Ni$1 \% \mathrm{Fe}-1.5 \% \mathrm{Co})$ after milling, (e) MA $(90 \% \mathrm{~W}, 6 \% \mathrm{Ni}$, and $4 \% \mathrm{Cu})$ before milling, and f) MA $(90 \% \mathrm{~W}, 6 \% \mathrm{Ni}$, and $4 \% \mathrm{Cu})$ after milling.

Table 2. Effect of milling time on the grain size of the WHA's powder fabricated by mechanical method.

\begin{tabular}{ccc}
\hline WHA's & $\begin{array}{c}\text { Time of } \\
\text { milling (hour) }\end{array}$ & $\begin{array}{c}\text { Grain Size } \\
\text { (nm) }\end{array}$ \\
\hline$(95 \% \mathrm{~W}-3.5 \% \mathrm{Ni}-1.5 \% \mathrm{Fe})$ & Zero & 157 \\
& 24 & 150 \\
& 48 & 76.8 \\
$(93 \% \mathrm{~W}-4.5 \% \mathrm{Ni}-1 \% \mathrm{Fe}-1.5 \% \mathrm{Co})$ & 72 & 70.2 \\
& 24 & 172.5 \\
& 48 & 99 \\
& 72 & 67.7 \\
$(90 \% \mathrm{~W}-6 \% \mathrm{Ni}-4 \% \mathrm{Cu})$ & Zero & 63.5 \\
& 24 & 99.8 \\
& 48 & 73.2 \\
\hline
\end{tabular}

The compacts were solid state sintered in vacuum furnace at temperature $1400^{\circ} \mathrm{C}$. Many studies proved that sintering temperature is related to the powder size, when the size is in nano-scale, the sintering temperature can be decreased up to several hundreds of degrees [25-27]. So solid state sintered in vacuum furnace at temperature $1400^{\circ} \mathrm{C}$ used in the present study.

\subsection{Characterization of WHA's}

\subsubsection{The Density of WHA's}

Table 3 compares the effect of fabrication method on the sintered density and densification parameter of the three investigated tungsten powder groups. It is worth noticing that irrespective of the fabrication method the compacts undergo significant densification during sintering. This can be attributed to the ultra-fine particle size of the powder used in this investigation. The data reveals that, the sintered density and densification parameter of the 
WHA powder compacts made by either chemical or mechanical method is high. The density ranged from 16.5 to $17.27 \mathrm{gm} / \mathrm{cm}^{-3}$, and the maximum density was reached at 17.0 and $17.28 \mathrm{gm} / \mathrm{cm}^{-3}$ for $(95 \% \mathrm{~W}-3.5 \% \mathrm{Ni}-1.5 \% \mathrm{Fe})$ WHA's fabricated by chemical reduction and mechanical method respectively, and the densification ranged from $94.2 \%$ to $99.1 \%$.

\subsubsection{The Microstructure of WHA's}

The experimental results reveal that the best sintering temperature for WHA's fabricated by either chemical or mechanical method was $1400^{\circ} \mathrm{C}$ for $1 \mathrm{~h}$. Figure 10 shows the microstructures of the sintered WHA's using optical microscopy. In WHA's, the tungsten particle generally present as polyhedral shape with regular microstructure of grain boundaries, that the diffusion in these polyhedral particles exhibit higher activation energy than the non-polyhedral particles as described by Hwany et al. [28]. Additionally, Figure 10 shows the porous-free metallograph for each $(95 \% \mathrm{~W}-3.5 \% \mathrm{Ni}-1.5 \% \mathrm{Fe}),(93 \% \mathrm{~W}-$ $4.5 \% \mathrm{Ni}-1.0 \% \mathrm{Fe}-1.5 \% \mathrm{Co})$ and $(90 \% \mathrm{~W}-6 \% \mathrm{Ni}-4 \% \mathrm{Cu})$ alloy as-sintered at $1400^{\circ} \mathrm{C}$ fabricated by mechanical or chemical reduction methods. These images illustrate two different phases area, the randomly distributed dark area phase surrounding the matrix phase (W) (white area).

The X-ray diffractions of the three groups of WHA's sintered at $1400^{\circ} \mathrm{C}$ for $1 \mathrm{hr}$ and fabricated by two techniques are shown in Figure 11. The patterns of the X-ray

Table 3. Comparison between density for both chemical and mechanical alloys sintered at $1400^{\circ} \mathrm{C}$.

\begin{tabular}{|c|c|c|c|c|}
\hline \multirow{2}{*}{ WHA's } & \multicolumn{2}{|c|}{ Density $\mathbf{g m} / \mathrm{cm}^{3}$} & \multicolumn{2}{|c|}{ Densification (\%) } \\
\hline & Chemical alloys & Mechanical alloys & Chemical alloys & Mechanical alloys \\
\hline$(93 \% \mathrm{~W}-4.5 \% \mathrm{Ni}-1 \% \mathrm{Fe}-1.5 \% \mathrm{Co})$ & 16.66 & 16.5 & 95.23 & 94.2 \\
\hline$(90 \% \mathrm{~W}-6 \% \mathrm{Ni}-4 \% \mathrm{Cu})$ & 16.85 & 16.7 & 99.1 & 98.2 \\
\hline
\end{tabular}

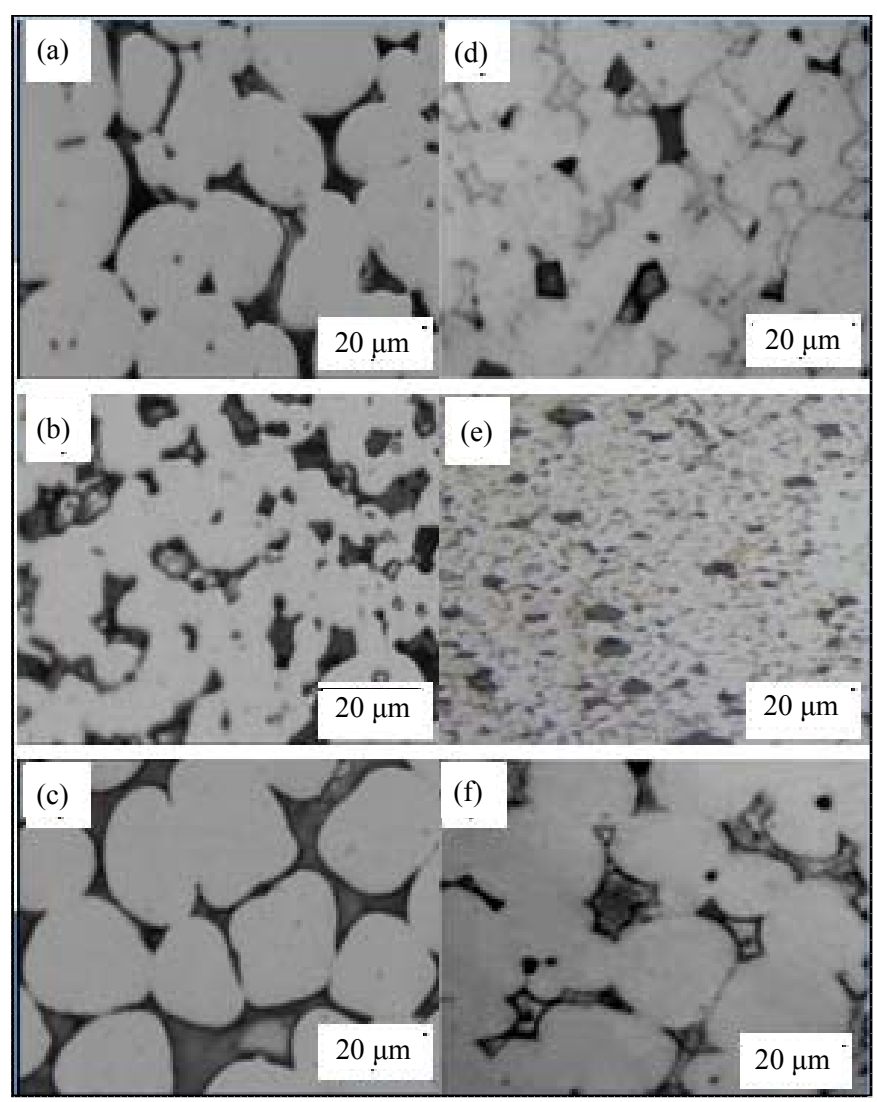

Figure 10. Optical microstructures of WHA's prepared by chemical and mechanical process, (a) mechanical alloy (95\%W-3.5\% Ni-1.5\%Fe), (b) mechanical alloy (93\%W-4.5\% Ni-1\%Fe-1.5\%Co), (c) mechanical alloy $(90 \% \mathrm{~W}-6 \% \mathrm{Ni}-4 \% \mathrm{Cu})$, (d) chemical alloy (95\% W-3.5\% Ni-1.5\%Fe), (e) chemical alloy (93\%W-4.5\%Ni-1\%Fe-1.5\%Co), (f) chemical alloy (90\%W$6 \% \mathrm{Ni}-4 \% \mathrm{Cu})$. 

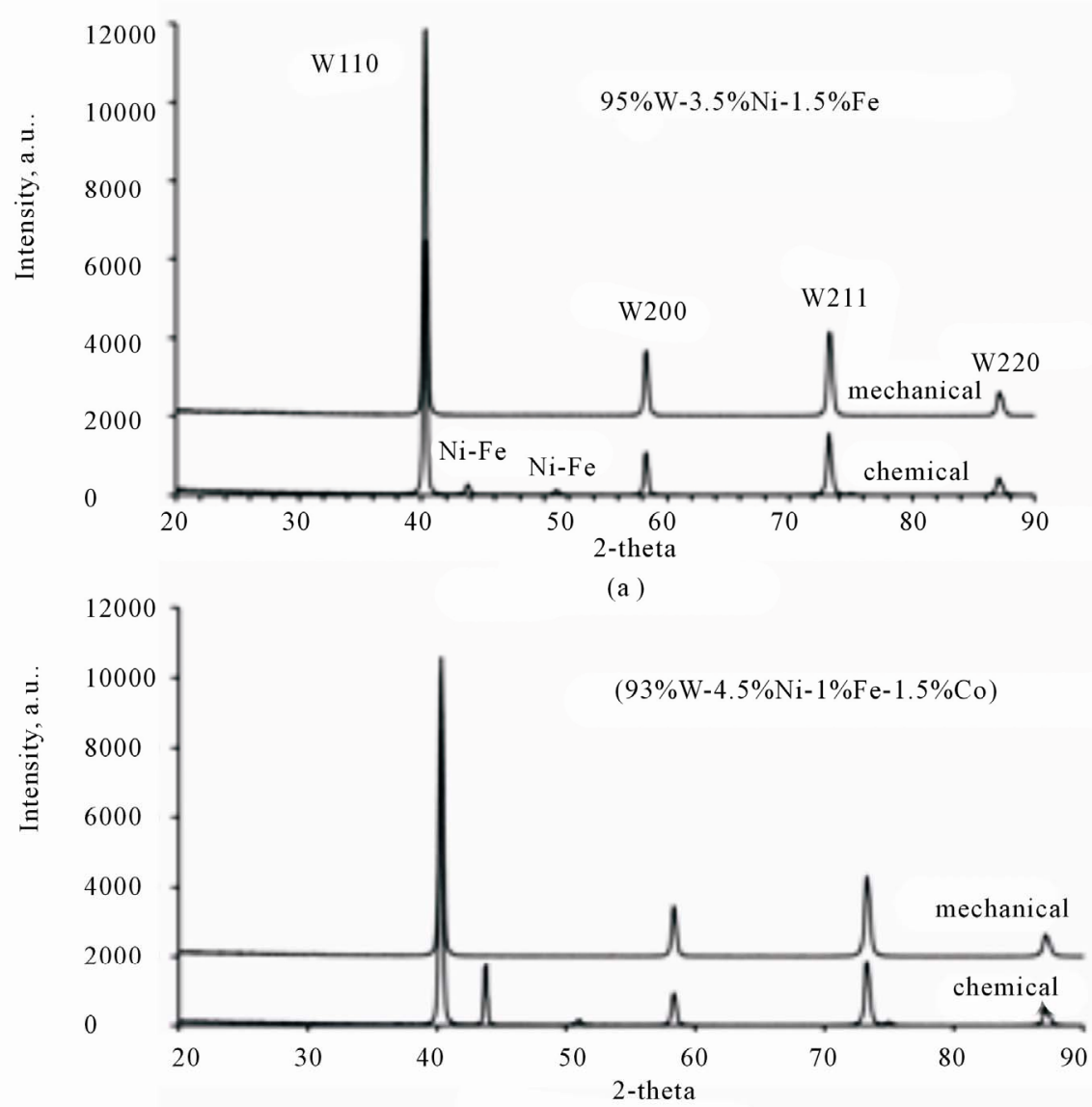

(b)

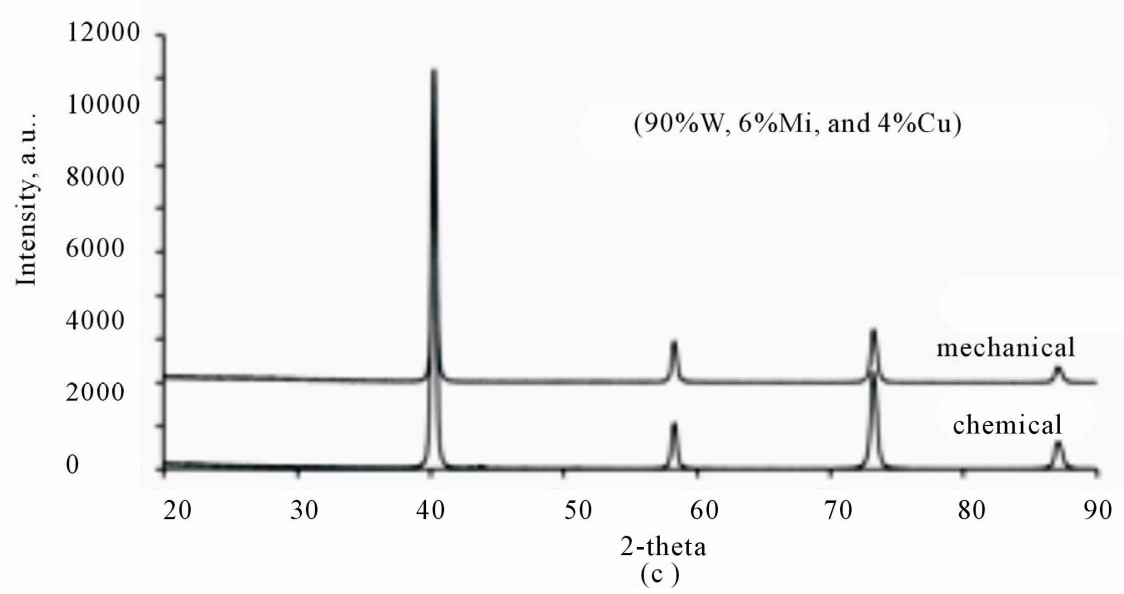

Figure 11. XRD of the three investigated alloys by chemical and mechanical technique after sintering at $1400^{\circ} \mathrm{C}$ where: (a) (95W-3.5Ni-1.5Fe), (b) (93\%W-4.5\% Ni-1\%Fe-1.5\%Co), and (c) $(90 \% \mathrm{~W}, 6 \% \mathrm{Ni}$, and $4 \% \mathrm{Cu})$.

for the alloys which fabricated by mechanical method illustrated the main peaks for bcc-structured tungsten phase (which is in very good agreement with the data of JCPDS file No. 04-0806). While the patterns of the X-ray diffraction for the alloys fabricated by chemical method revealed the main peaks for tungsten and two relatively weak peaks which corresponding to Ni-Fe solid solution phase for $(95 \% \mathrm{~W}-3.5 \% \mathrm{Ni}-1.5 \% \mathrm{Fe})$ and $(93 \% \mathrm{~W}-4.5 \% \mathrm{Ni}-$
$1 \% \mathrm{Fe}-1.5 \% \mathrm{Co}$ ) alloys.

The grain size of the three different WHA's and fabricated by two techniques is shown in Table 4 . The data illustrated that the grain size of these alloys reach to the nano-scaled dimension. Additionally, the results reveal that the grain size of the alloy fabricated by chemical technique is less slightly than that fabricated by mechanical technique. This indicates that the chemical 
Table 4. The grain size of sintered WHA's fabricated by mechanical and chemical techniques.

\begin{tabular}{ccc}
\hline \multirow{2}{*}{ WHA's } & \multicolumn{2}{c}{ Grain Size (nm) } \\
\cline { 2 - 3 } & $\begin{array}{c}\text { Chemical } \\
\text { alloy }\end{array}$ & $\begin{array}{c}\text { Mechanical } \\
\text { alloy }\end{array}$ \\
\hline$(95 \% \mathrm{~W}-3.5 \% \mathrm{Ni}-1.5 \% \mathrm{Fe})$ & 63.8 & 71.4 \\
$(93 \% \mathrm{~W}-4.5 \% \mathrm{Ni}-1 \% \mathrm{Fe}-1.5 \% \mathrm{Co})$ & 62.9 & 63.9 \\
$(90 \% \mathrm{~W}-6 \% \mathrm{Ni}-4 \% \mathrm{Cu})$ & 53.1 & 56.4 \\
\hline
\end{tabular}

method produce alloys with fine grain size.

\subsubsection{Hardness Measurement}

The microhardness for the three investigated alloys fabricated by chemical and mechanical methods is shown in Table 5. The data reveals that the micro hardness of the all alloys fabricated by chemical or mechanical methods ranged from 430 to $475 \mathrm{Hv}$. The increase of hardness for the samples sintered is suggested contributing by the formation of fine nano tungsten solid solution phase.

\subsubsection{Electrical Resistivity and Thermal Conductivity Measurement}

Table 6 illustrates the electrical resistivity and thermal conductivity values of the all fabricated alloys. It is clear that the electrical resistivity $(\mu \Omega \cdot \mathrm{cm})$ for all WHA's fabricated by chemical methods is lower than that fabricated by mechanical method. This can be rationalized by the fine grains of the alloy fabricated by chemical method which led to increase the mobility of the free electron causing low resistivity. Additionally, the data reveals that the thermal conductivity of the WHAs fabricated by chemical method is higher than that fabricated by mechanical method.

\subsubsection{Transverse Rupture Strength (TRS)}

The variations of transverse rupture strength of the different sintered alloys fabricated by chemical or mechanical methods are shown in Table 7. According to the data obtained, the TRS of the alloyed fabricated by mechaniccal method is higher than that fabricated by chemical method. The maximum TRS of $977 \pm 40 \mathrm{~N} / \mathrm{mm}^{2}$ was obtained for the $90 \% \mathrm{~W}-6 \% \mathrm{Ni}-4 \% \mathrm{Cu}$ alloy sintered at $1400^{\circ} \mathrm{C}$ fabricated by mechanical method and 700 $\mathrm{N} / \mathrm{mm}^{2}$ was obtained for the same alloy fabricated by chemical method.

\section{Conclusions}

The solid phase sintered of $(95 \mathrm{~W}-3.5 \% \mathrm{Ni}-1.5 \% \mathrm{Fe})$, $(93 \mathrm{~W}-4.5 \% \mathrm{Ni}-1.0 \% \mathrm{Fe}-1.5 \% \mathrm{Co})$, and $(90 \mathrm{~W}-6 \% \mathrm{Ni}-$

Table 5. Comparison between microhardness for both chemical and mechanical WHA's sintered at $1400^{\circ} \mathrm{C}$.

\begin{tabular}{ccc}
\hline WHA's & \multicolumn{2}{c}{${\text { Microhardness, } \mathbf{H V}_{\mathbf{( 5 0 0} \text { g) }} \pm \mathbf{3 0}}^{\text {Mechanical alloy }}$} \\
\cline { 2 - 3 }$(95 \% \mathrm{~W}-3.5 \% \mathrm{Ni}-1.5 \% \mathrm{Fe})$ & Chemical alloy & 430 \\
$(93 \% \mathrm{~W}-4.5 \% \mathrm{Ni}-1 \% \mathrm{Fe}-1.5 \% \mathrm{Co})$ & 440 & 457 \\
$(90 \% \mathrm{~W}-6 \% \mathrm{Ni}-4 \% \mathrm{Cu})$ & 475 & 437 \\
\hline
\end{tabular}

Table 6. Comparison between electrical resistivity and thermal conductivity for both chemical and mechanical WHA's sintered at $1400^{\circ} \mathrm{C}$.

\begin{tabular}{ccccc}
\hline \multirow{2}{*}{ WHA's } & \multicolumn{2}{c}{ Electrical resistivity $\left(\boldsymbol{\mu} \Omega \cdot \mathbf{c m}^{-\mathbf{1}}\right)$} & \multicolumn{2}{c}{ Thermal conductivity, $\lambda \mathbf{W} / \mathbf{m K}$} \\
\cline { 2 - 5 } & Chemical alloys & Mechanical alloys & Chemical alloys & Mechanical alloys \\
\hline$(95 \% \mathrm{~W}-3.5 \% \mathrm{Ni}-1.5 \% \mathrm{Fe})$ & 8.8 & 10.6 & 83.28 & 68.14 \\
$(93 \% \mathrm{~W}-4.5 \% \mathrm{Ni}-1 \% \mathrm{Fe}-1.5 \% \mathrm{Co})$ & 8.5 & 12.5 & 86.22 & 58.63 \\
$(90 \% \mathrm{~W}-6 \% \mathrm{Ni}-4 \% \mathrm{Cu})$ & 9.5 & 11.9 & 77.14 & 61.58 \\
\hline
\end{tabular}

Table 7. Comparison between TRS for both chemical and mechanical WHA's sintered at $1400^{\circ} \mathrm{C}$.

\begin{tabular}{ccc}
\hline WHA's & \multicolumn{2}{c}{ TRS, N/mm $\mathbf{m}^{2} \pm \mathbf{4 0}$} \\
\cline { 2 - 3 } & Chemical alloys & Mechanical alloys \\
\hline$(95 \% \mathrm{~W}-3.5 \% \mathrm{Ni}-1.5 \% \mathrm{Fe})$ & 723.26 & 684.61 \\
$(93 \% \mathrm{~W}-4.5 \% \mathrm{Ni}-1 \% \mathrm{Fe}-1.5 \% \mathrm{Co})$ & 694.868 & 600.00 \\
$(90 \% \mathrm{~W}-6 \% \mathrm{Ni}-4 \% \mathrm{Cu})$ & 977.20 & 700.00 \\
\hline
\end{tabular}


$4 \% \mathrm{Cu})$ WHA's has been prepared using chemical and mechanical techniques. The WHA's fabricated by chemical reduction or mechanical techniques were characterized by X-ray diffraction, SEM, and TEM techniques. The results of this study can be summarized as follow:

1) Milling prior to fabricating WHA's by mechanical technique is helpful to preparing fine grain and good property. The sequences of structural sizes and/or phase transformation and the behavior of mechanically alloyed powders have been assessed using XRD and TEM microscopy. The results reveal that the grain size decreases with increasing milling time in all three groups. The apparent crystallite size of these mechanical alloys reaches to the nano-scaled dimension. This agrees closely with measuring by TEM observation. Additionally, X-ray patterns of WHA's powders after mechanical milling 72 hrs proved that the crystal size ranged from 63.5 to 71.5 $\mathrm{nm}$.

2) X-ray diffraction of the sintered alloys revealed that the bcc (body centered cubic) solid solution tungsten phase formed with WHA's fabricated by mechanical and chemical reduction techniques after sintering at $1400^{\circ} \mathrm{C}$ while, the fcc (face centered cubic) Fe-Ni solid solution phase formed only with the chemical reduction technique, indicating that composite powders are well synthesized by chemical reduction process.

3) TEM observation revealed the formation of nano tungsten solid solution phase.

4) The grain size of the matrix phase after sintering is arranged from 53.1 to $63.8 \mathrm{~nm}$ for the alloys fabricated by chemical reduction technique and from 56.4 to 71.4 $\mathrm{nm}$ for the alloys fabricated by mechanical technique.

5) The microhardness of WHA's sintered at $1400^{\circ} \mathrm{C}$ for $1 \mathrm{~h}$ fabricated by either chemical reduction or mechanical technique is ranged from 430 to $475 \mathrm{Hv}$. The increasing of hardness for the WHA's is due to the formation of nano tungsten solid solution phase.

The TRS of the alloyed fabricated by chemical method is higher than that fabricated by mechanical method.

\section{Acknowledgements}

The authors gratefully acknowledged the financial support from Science \& Technology Development Fund (STDF) (Grant No. ID 55). Additionally, I would like to thank Prof. Sayed Farag Moustafa, Prof. of Powder Technology, and asking Allah to rest his soul in Heaven, where he was suggesting the line of project investigated. He was as a godfather for us in the work.

\section{REFERENCES}

[1] R. Gero, L. Borukhin and I. Pikus, "Some Structural Effects of Plastic Deformation on Tungsten Heavy Metal Alloys," Materials Science and Engineering: A, Vol. 302,
No. 1, 2001, pp. 162-167. doi:10.1016/S0921-5093(00)01369-1

[2] W. S. Lee, G. L. Xiea and C. F. Lin, "The Strain Rate and Temperature Dependence of the Dynamic Impact Response of Tungsten Composite," Materials Science and Engineering: A, Vol. 257, No. 2, 1998, pp. 256-267. doi:10.1016/S0921-5093(98)00852-1

[3] I. S. Humail, F. Akhtar, S. J. Askari, M. Tufail and X. H $\mathrm{Qu}$, "Tensile Behavior Change Depending on the Varying Tungsten Content of W-Ni-Fe Alloys," International Journal of Refractory Metals and Hard Materials, Vol. 25, No. 5-6, 2007, pp. 380-385. doi:10.1016/j.ijrmhm.2006.12.003

[4] J. L. Fan, X. Gong, B. Y. Huang, M. Song, T. Liu, J. M. Tian, "Densification Behavior of Nanocrystalline W-NiFe Composite Powder Prepared by Sol-Spray Drying and Hydrogen Reduction Process," Journal of Alloys and Compounds, Vol. 489, No. 1, 2010, pp. 188-194.

doi:10.1016/j.jallcom.2009.09.050

[5] J. L. Fan, X. Gong, B. Y. Huang, M. Song, T. Liu and M. G. Qi, "Dynamic Failure and Adiabatic Shear Bands in Fine Grain 93W-4.9Ni-2.1Fe Alloy with $\mathrm{Y}_{2} \mathrm{O}_{3}$ Addition under Lower High-Strain-Rate, (HSR) Compression," Mechanics of Materials, Vol. 42, No. 1, 2010, pp. 24-30. doi:10.1016/j.mechmat.2009.08.006

[6] X. Gong, J. L. Fan, B. Y. Huang and J. M. Tian, "Microstructure Characteristics and a Deformation Mechanism of Fine-Grained Tungsten Heavy Alloys under High Strain Rate Compression," Materials Science and Engineering: A, Vol. 527, No. 29-30, 2010, pp. 7565-7570. doi:10.1016/j.msea.2010.07.102

[7] R. M. German, In: A. Bose and R. J. Dowding, Eds., Proceedings of the International Conference on Tungsten and Tungsten Alloys, MPIF, New Jersey, 1992, p. 3.

[8] W. D. Cai, Y. Li, R. J. Dowding, F. A. Mohamed and E. J. Lavernia, "A Review of Tungsten-Based Alloys as Kinetic Energy Penetrator Materials," Review of Particulate Materials, Vol. 3, No. 1, 1995, pp. 71-132.

[9] Y. Wu, R. M. German, B. Marx, P. Suri and R. Bollina, "Comparison of Densification and Distortion Behaviors of W-Ni-Cu and W-Ni-Fe Heavy Alloys in Liquid-Phase Sintering," Journal of Materials Science, Vol. 38, No. 10, 2003, pp. 2271-2281. doi:10.1023/A:1023725508608

[10] B. Huang, J. Fan, S. Liang and X. Qu, "The Rheological and Sintering Behavior of W-Ni-Fe Nano-Structured Crystalline Powder," Journal of Materials Processing Technology, Vol. 137, No. 1-3, 2003, pp. 177-182. doi:10.1016/S0924-0136(02)01090-7

[11] S. H. Hong and H. J. Ryu, "Combination of Mechanical Alloying and Two-Stage Sintering of a 93W-5.6Ni-1.4Fe Tungsten Heavy Alloy," Materials Science and Engineering: $A$, Vol. 344, No. 1-2, 2003, pp. 253-260. doi:10.1016/S0921-5093(02)00410-0

[12] F. He, M. Wang and X. Lu, "Properties of Electrodeposited Amorphous Fe-Ni-W Alloy Deposits," Transactions of Nonferrous Metals Society of China, Vol. 16, No. 6, 2006, pp. 1289-1294. doi:10.1016/S1003-6326(07)60008-9

[13] M. Donten, H. Cesiulis and Z. Stojek, "Electrodeposition 
and Properties of Ni-W, Fe-W and Fe-Ni-W Amorphous Alloys. A Comparative Study," Electrochimica Acta, Vol. 45, No. 20, 2000, pp. 3389-3396. doi:10.1016/S0013-4686(00)00437-0

[14] B. H. Kear, "Sintering and Microstructure of Nanophase WC/Co Hardmetals," Journal of Materials Processing Technology, Vol. 63, No. 1-3, 1997, pp. 317-321. doi:10.1016/S0924-0136(96)02748-3

[15] P. Seegopaul, L. E. McCandlish and F. M. Shinneman, "Production Capability and Powder Processing Methods for Nanostructured WC-Co Powder," International Journal of Refractory Metals and Hard Material, Vol. 15, No. 1-3, 1997, pp. 133-138. doi:10.1016/S0263-4368(96)00044-3

[16] L. Dong-Won, T. Farkhod, K. Ju-Hyeong and Y. Ming Chuan, "Fabrication of Ultrafine Tungsten-Based Alloy Powders by Novel Soda Reduction Process," Materials Research Bulletin, Vol. 45, No. 3, 2010, pp. 348-351. doi:10.1016/j.materresbull.2009.12.005

[17] Z. W. Zhang, G. L. Chen, G. Chen and J. E. Zhou, "Amorphization and Thermal Stability of Mechanical Alloyed W-Ni-Fe," Materials Science and Engineering: A, Vol. 41, No. 7, 2006, pp. 34-39. doi:10.1016/j.msea.2005.06.080

[18] Z. W. Zhang, J. E. Zhou, S. Q. Xi, G. Ran and P. L. Li, "Phase Transformation and Thermal Stability of Mechanically Alloyed W-Ni-Fe Composite Materials," Materials Science and Engineering: A, Vol. 379, No. 1-2, 2004, pp. 148-53. doi:10.1016/j.msea.2004.02.039

[19] Z. W. Zhang, J. E. Zhou, S. Q. Xi, G. Ran, P. L. Li and W. $\mathrm{X}$. Zhang, "Formation of Crystalline and Amorphous Solid Solutions of W-Ni-Fe Powder during Mechanical Alloying," Journal of Alloys and Compounds, Vol. 370, No. 1-2, 2004, pp. 186-191. doi:10.1016/j.jallcom.2003.09.012

[20] Z. G. Liu, L. Lu and M. O. Lai, "Synthesis of Nanocrystalline Carbide in Tungsten Alloy by Mechanical Alloying and Annealing," Journal of Alloys and Compounds,
Vol. 394, No. 1-2, 2005, pp. 176-180. doi:10.1016/j.jallcom.2004.10.027

[21] J. S. C. Jang, J. C. Fwu and L. J. Chang, "Study on the Solid-Phase Sintering of the Nano-Structured Heavy Tungsten Alloy Powder," Journal of Alloys and Compounds, Vol. 434-435, 2007, pp. 367-370. doi:10.1016/j.jallcom.2006.08.215

[22] G. O. Bahig, "Effect of Various Binder Metals on Tungsten Properties," M.Sc. Thesis, Cairo University, Giza, 2006.

[23] D. L. Deborah Chung, "Applied Materials Science, Application of Engineering Materials in Structural, Electronics, Thermal and Other Industries," Chapman and Hall CRC., 2001.

[24] E. Lassner and W. D. Schubert, "Tungsten; Properties, Chemistry, Technology of the Element, Alloys, and Chemical Compounds," Kluwer Academic/Pienum Publishers, New York, 1998.

[25] R. Malewar, K. S. Kumar, B. S. Murty, B. Sarma and S. K. Pabi, "On Sinterability of Nanostructured W Produced by High-Energy Ball Milling," Journal of Materials Research, Vol. 22, No. 5, 2007, pp. 1200-1206. doi:10.1557/jmr.2007.0166

[26] J. L. Johnson, "Progress in Processing Nanoscale Refractory and Hardmetal Powders," Proceeding of International Conference on Tungsten Refractory \& Hardmetals VII, Vol. 5, No. 57, 2008, pp. 5-71.

[27] H. Wang, Z. Fang and D. Siddle, "Study of Size-Dependent Sintering Behavior of Tungsten Powders," In: Tungsten, Refractory \& Hardmetals VII, Metal Powder Industries Federation, Princeton, 2008, pp. 5-72.

[28] N. M. Hwany, Y. J. Park, D.-Y. Kim and D. Y. Yoon, "Activated Sintering of Nickel-Doped Tungsten: Approach by Grain Boundary Structural Tramsition," Scripta Materialia, Vol. 42, No. 5, 2002, pp. 422-428. 